ANALYSIS ON THE PREVALENCE AND PERCEIVED CONSEQUENCES OF EARLY MARRIAGE ON SCHOOL ENROLMENT, COMPLETION AND ACADEMIC PERFORMANCE OF FEMALE STUDENTS IN SENIOR SECONDARY SCHOOLS IN THE NORTH-EAST GEO-POLITICAL ZONE, NIGERIA: A COUNSELLOR-REFLECTION.

BY

MOHAMMED AYUBA

SCHOOL OF EDUCATION

DEPARTMENT OF EDUCATIONAL FOUNDATION

GSM: +2347037106019

Email: mayubahdj@gmail.com

JIGAWA STATE COLLEGE OF EDUCATION, GUMEL

\&

MUS'AB SHU'AIBU (Ph.D.)

SCHOOL OF EDUCATION

DEPARTMENT OF PSYCHOLOGY

G.S.M: +2347068290667

Email: musabshuaiburingim@gmail.com

JIGAWA STATE COLLEGE OF EDUCATION, GUMEL 


\title{
ANALYSIS ON THE PREVALENCE AND PERCEIVED CONSEQUENCES OF EARLY MARRIAGE ON SCHOOL ENROLMENT, COMPLETION AND ACADEMIC PERFORMANCE OF FEMALE STUDENTS IN SENIOR SECONDARY SCHOOLS IN THE NORTH-EAST GEO-POLITICAL ZONE, NIGERIA: A COUNSELLOR-REFLECTION.
}

\author{
Muhammad (A.) \\ Jigawa State College of Education Gumel, Nigeria \\ mayubahdj@gmail.com/+2347037106019 \\ \& \\ Mus'abu (S.) (PhD.) \\ Jigawa State College of Education Gumel, Nigeria \\ musabushuaiburingim@gmail.com/+2347068290667
}

\begin{abstract}
This paper ventured on the analysis of the prevalence and perceived consequences of early marriage on school enrollment completion and academic performance of female students in senior secondary schools in the North-East Geo-political zone, Nigeria. The objective of the study is to determine the major effects of early marriage on female youth educational development. Ex-post facto design was used for the study. Three hundred and fifty four (354) females' students for 2015/2016 session constituted sample respondents for the study. They responded to prevalence and perceived consequences of early marriage questionnaire (PCEMQ) while the sample of female student senior secondary school certificate (SSCE) qualifying examination results for the 2015/2016 session was used for the analysis of student academic achievement in English, Mathematics and Biology. The data were analyzed with the statistical package for social science (SPSS) using t-test of inferential statistics $i$-e. T-test of dependent and independent sample to determine the significance different between the variables on enrolment, completion and academic performance. The major finding revealed that, there was significant different in enrolment completion and academic performance of early marriage students and those married at a later age. It was further recommended that, there is need for a reform in laws discouraging early/force marriage in the country. Also guidance and counselling should be introduced in all schools, and parents should delay marriage of their daughters until at a later age.
\end{abstract}

\section{KEY WORDS: EARLY MARRIAGE, SCHOOL COMPLETION, ACADEMIC PERFORMANCE AND COUNSELLING INTERVENTION.}




\section{INTRODUCTION}

However, Marriage is viewed by different people in different ways, mainly because of the ethno cultural diversities and religious beliefs in the system of marriages throughout the world. Early marriage refers to the marriage contracted before the usual expected age, depending on the culture or religion, place or nation. Indeed, early marriage in the area under study is normally arranged by parents, relatives or guardian to avoid social harassment. These and many others have attracted some researchers i.e. conger (2003:310 - 325) wrote extensively on this aspect; in our society, the role requirements associated with marriage is complex and often difficult to fulfill. The burdens are likely to be greater for married adolescents who may still be struggling to complete their education. Conger added that, the girls whether working or not may have to meet the responsibilities of social interactions, the complex task of running the home and children rearing often without the aid and support to the extended family of the earlier day, the issue of overburdening task for individual marriage and pursuing their education, and those who after marriage can no longer continue with their education are all issues cross examined in this paper. However students' enrolment has become a challenging problem for the academic community; therefore an effective Program for student retention must be implemented in order to increase the completion of qualified Students. Institution must work towards providing students with meaningful learning environments so that these students will become connected to the institution by developing a sense of belonging with the students' body. Therefore, every effort must be made to retain students while they are on campus. In the past, comprehensive studies have concluded that Institutional factors such as faculty student relationships and innovative teaching methods can significantly motivate and challenge students to learn and stay in schools. 
This study has indeed highlighted improved primary and secondary school enrolment rates for girls. Girls who have dropped out of school or not been enrolled in the first place are likely to be pushed into early marriage. However, students' enrolment has become a challenging problem for the academic community. Therefore, an effective program for students' retention must be implemented in order to increase the completion of qualified students. Institutions must work towards providing students with meaningful learning environments so that these students will become connected to the institutions by developing a sense of belonging with the students' body.

\section{Significance of the Study}

$\checkmark$ The purpose of this study is to find out the major effects of early marriage on academic performance between female students who married early and those who married at later age.

$\checkmark$ The Significant of the study is to find out the major effects of early marriage on school enrolments, completion and academic performance of married female students and those who married at a later age.

$\checkmark$ To identify the major effects of counseling intervention on academic achievements of married female students and those that have not been given intervention.

\section{Research Questions}

- Does early marriage among female students affect enrolment and academic performance?

- Does early marriage among female students affect completion and academic performance?

- Does early marriage among female students affect enrolments, completion and academic performance? 


\section{Research Hypotheses}

- There is no significant difference in academic performance of students who marry early and those married at later age.

- There is no significant difference in academic performance between the enrolled early married students and those who completed and marry at a later age.

- There is no significant difference in academic performance between married students that have received suitable counseling intervention and those that have not been given.

\section{Population and Sample}

The population of this study comprises of all the female students (married and unmarried) for senior secondary schools in the northwest, Nigeria the student's population sampled was one hundred and twenty 120 out of 480 married students from the sampled schools. However, accessible populations of married girls were drawn from two government day (male/female) senior secondary schools randomly selected within the sampled schools. This was to ensure quality of the research. Thus, the target population was indeed for all the married girls in the female senior secondary schools in the north-western states.

\section{Data Analysis Procedure}

Due to inferential nature of the study, background data obtained from the respondents were interpreted and analysis using parametric tests of inferential statistics i.e. t-test of independent sample. However, the presentation and discussion of results were carried out around the research hypotheses which have guided the analysis. 


\section{Hypothesis Testing}

Hypothesis (1) there is no significant difference in academic performance of students who married early and those who married at later age.

In testing the above hypothesis, mean scores of courses taught by students academic achievements were obtained, tabulated computed using $\mathrm{t}$ - test of unrelated sampled. In order to find out whether there is no significant difference in academic performance between students who marry early and those who married at later age. Here, a medium of 60 students has been used and calculated as follows:

Table 1: Calculated mean and standard deviation

\begin{tabular}{|l|l|l|}
\hline & Married & Married at a later age (x) \\
\hline Mean & 40.4 & 64.4 \\
\hline Standard deviation & 6.74 & 9.82 \\
\hline
\end{tabular}

Let, the level of Significant at which the test conducted be at 0.05 , we calculated the t-test as follows:

Table 2: t-test calculated between married and those married at a later age

\begin{tabular}{|l|l|l|l|l|l|l|l|l|}
\hline & Mean & $\begin{array}{l}\text { Std } \\
\text { Deviation }\end{array}$ & N & Df & Std. & T-cal & T- & L.S \\
& & 6.74 & 12 & 11 & 1.6 & 3.93 & 1.98 & 0.05 \\
\hline Married Students & 40.4 & 6.74 & & & & & & \\
\hline Married at later age & 64.6 & 9.82 & 0 & 8 & & & & \\
\hline
\end{tabular}


Hence, $\mathrm{t}$-calculated is equal to 3.93 which is greater than $\mathrm{t}$ - critical 1.98 , at.05 level of Significant. The hypothesis which stated that, there is no significant difference in academic performance between early marriage students and those who married at a later age was rejected.

\section{Hypothesis (ii)}

There is no significant difference in academic performance between the enrolled early married and those who completed and married at a later age.

In order to test the above hypothesis, mean of responses and courses taught were obtained and analyzed using unrelated $t$ - test sampled. To find out whether there is no significant difference in academic performance between the enrollment of early married students and those who completed and married at a later age.

Table 3: Summary Table for Means and Variance

\begin{tabular}{|l|l|l|}
\hline & Enrolment of early married students & Completed schooling at a later age \\
\hline Mean & 68 & 119 \\
\hline Variance & 104 & 246 \\
\hline
\end{tabular}

Table 4: the calculated t-test could be summarized below

\begin{tabular}{|l|l|l|l|l|l|l|l|l|}
\hline & Mean & $\begin{array}{l}\text { Std } \\
\text { Deviation }\end{array}$ & N & Df & $\begin{array}{l}\text { Std. } \\
\text { Error }\end{array}$ & $\begin{array}{l}\text { T- } \\
\text { cal }\end{array}$ & T-crit & L.S \\
\hline Completing school at a later age & 119 & 246 & & & & & & \\
\hline Enrollment of married students & 68 & 104 & 120 & 118 & 1.2 & 46.5 & 1.98 & 0.05 \\
\hline
\end{tabular}

- Hence, the t-calculated 46.5 is greater than t-critical 1.98 at 0.05 been the chosen level of Significance, So, We reject the null hypothesis, which stated that, there is no Significant difference between enrollments of early married students and those students who completed and 
married at a later age. Hence, we can con conclude that those who completed schooling and married at a later age performed scientifically better.

\begin{tabular}{|l|l|l|l|l|l|l|l|l|}
\hline & Mean & $\begin{array}{l}\text { Std } \\
\text { Deviation }\end{array}$ & N & Df & Std. & T-Cal & T-Crit & L.S \\
\hline Completing school at a later age & 56.8 & 8.72 & 120 & 118 & 1.21 & 4.79 & 1.98 & 0.05 \\
\hline Enrollment of married students & 42.6 & 6.9 & & & & & & \\
\hline
\end{tabular}

\section{Hypothesis three 3}

There is no significant difference in academic performance between married students that have received counseling intervention and those that have not been given

In order to test the above hypothesis mean of responses and courses taught were obtained and analyzed using unrelated t-test sampled. To find out whether there is no significant difference in academic performance between married students that have received counseling intervention and those that have not been given. Hence, the t-calculated is greater than the critical t-value. In other words, the evidence from the data tends to be supportive of the alternative hypothesis. It implies that, the counseling group performs significantly better than the non counseling group. Hence, we can conclude that the use of counseling intervention facilitates female students' performance than the use of non-counseling. Moreover, early marriage is more common in Jigawa State, numerous students are not in school, and those lucky to be enrolled in school dropout before completion and the level of educational achievement students attain is often low. These problems affect girls more than boys. Since, most of the parents in Jigawa State Nigeria are not educated; there is urgent need for campaign for female education with a view to encouraging more parents to send their female children to schools. 


\section{REFERENCE}

Adetunde, I. A. (2008). Factors affecting the standard of female Education:A case Study of Senior Secondary Schools in the Kassena - Nankana District. Journal of Social Sciences4(4):ISSN 1549 - 3652.

Alkali, S. (1998). Effects of Early Marriage on Academic Achievement of Female Secondary School Students in Jigawa State. Unpublished B.A Dissertation, Bayero University, Kano.

Barrier S., Benefits, and Policies, World Bank Publications, ISBN:0801858283, PP:352.

Bayer, A.E (2000): Early Dating Early Marriage. Ibadan: Journal of Marriage and the FamilyVoI.44p. 638.

Bichi, M.Y. (1977). The Effect of some Home Background Factors on The Academic Achievement of Primary School Children. Kano Unpublished (M.ED) dissertation B.U.K.

Engine-Dehir, A. (2009). Girls Participation in Education, New York; Norton.

King and Hill C. (2010). Female Education, London Cambridge University Press.

King, E.M. \& A.H. Khan, 1993. Women in Developing Countries. Kolo, F.D (2010). Professional Development and Teacher Education in Nigeria, Zaria: ABU, Zaria.

Lodewijk, H.M. (2011, September, 12) professionalization and Teacher Education. Current issues in Social Psychology, 6 (2) 186-190. Retrieved fromhttp://www.cassonnigeria.org/edu.prod

Mialaret, G. 1995. The Ethtcation of Girls and women in Africa. FAME, Nairobi, pp: 173 - 249.

Mus'ab, S. (2003). Effect of Early Marriage on School Retention, Completion and Academic performance of female student, in Selected Secondary School in Jigawa State: Unpublished Ph.D Thesis Uni- Abuja.

Nash, (1996). Introduction to Persona - Social Marriage Relationship and School Retention of Youth. New York H.B.

Noel, Levitz, \&Saluri, (1985). Guidance for Schools and Dropout among Students. New York 12 $-164$.

Nwoye, A.(1991). Marriage and Family Counseling: (1985, March 21st) National Concord, p.12

Odinkenue, L.N. (1978): The Main Course of Unhappy Marriage in Nigeria Society. Jos; Bright Publication. 
Terenzimi, etal. (1996). Dropout for Marriage. New York; Norton.

Uba A. (1980), the Effect of Socio-Economic Status on the Academic Achievements of Secondary School Students, Jos; Savanna Press.

Vincent, T. (1987). Academic Attitudes and Interest. London Cambridge University, Press. 